\title{
Mental Health among Internet Addicts and Non Addict Peoples Behaviour
}

\author{
Dr. S. M. Makvana ${ }^{1}$, Pratika C. Sankhesara ${ }^{2 *}$
}

\section{ABSTRACT}

The present study aimed to examine the relationship between Mental Health among Internet Addicts and Non Addicts with reference to types of Internet effect and Gender. While almost everyone has experienced mental health at some point in their lives, most do not develop longterm problems with mental health. Mental health it is the Latin world "anger" it means "strangle" it use to present period changing from individual values -morale, idea, alienation, competition and achievement. WHO (World Health Organization),defined mental health is "A state of well-being in which the individual realizes his or her own abilities, can cope with the normal stresses of life, can work productively and fruitfully, and is able to make a contribution to his or her community". WHO stresses that mental health "is not just the absence of mental disorder". According to Medilexicon's medical dictionary, defined mental health is "emotional, behavioral, and social maturity or normality; the absence of a mental or behavioral disorder; a state of psychological well-being in which one has achieved a satisfactory integration of one's instinctual drives acceptable to both 4 oneself and one's social milieu; an appropriate balance of love, work, and leisure pursuits". The present studies used to variables namely (A) Types of Addicts (B) types of Gender examine the effect of mental health. The scales used Mental Health Inventory (1992) Constructed \& standardized by Dr D. J. Bhatt. The scale consisted in five factors. A research Data/sample size 480 was collected from Internet Addicts and Non Addicts people of Ahmadabad district of Gujarat State. Hence, this gives rise to a 2 x 2 factorial research design for the analysis of the data. The ANOVAs, was re-sorted in order to get the results. There is no significant effect of Internet Addicts and Non Addicts people with regard to mental health. There is significant effect of gender (male and female) on mental health.

Keywords: Internet addict and non addict, Gender, Ahmadabad District, and Gujarat state

Mental health is not just the absence of mental disorder. It is defined as a state of well-being in which every individual realizes his or her own potential, can cope with the normal stresses of

\footnotetext{
${ }^{1}$ Professor, Department of Psychology, Sardar Patel University, Vallabhvidyanagar, Gujarat State

${ }^{2}$ Researcher, Department of Psychology, Sardar Patel University, Vallabhvidyanagar, Gujarat State *Corresponding Author (c) 2015 I S Makvana, P Sankhesara; licensee IJIP. This is an Open Access Research distributed under the terms of the Creative Commons Attribution License (http://creativecommons.org/licenses/by/2.0), which permits unrestricted use, distribution, and reproduction in any Medium, provided the original work is properly cited.
} 


\section{Mental Health among Internet Addicts and Non Addict Peoples Behaviour}

life, can work productively and fruitfully, and is able to make a contribution to her or his community.

In most countries, particularly low- and middle-income countries, mental health services are severely short of resources - both human and financial. Of the health care resources available, most are currently spent on the specialized treatment and care of the people with mental illness, and to a lesser extent on an integrated mental health system. Instead of providing care in large psychiatric hospitals, countries should integrate mental health into primary health care, provide mental health care in general hospitals and develop community-based mental health services.

Even less funding is available for mental health promotion, an umbrella term that covers a variety of strategies, all aimed at having a positive effect on mental health well-being in general. The encouragement of individual resources and skills, and improvements in the socio-economic environment are among the strategies used.

Mental health promotion requires multi-sectoral action, involving a number of government sectors and non-governmental or community-based organizations. The focus should be on promoting mental health throughout the lifespan to ensure a healthy start in life for children and to prevent mental disorders in adulthood and old age.

Definition of Mental health:

Suler (1999) points out those addictions are not actually defined very clearly. This is because it can be unhealthy or even healthy and also a combination of both. It is clear that when people are satisfied by some activities such as hobbies, they would like to spend their times on these activities as much as possible. In addition, it can also be creativity, learning and self-expression. Despite of this, some psychologists define addiction as a behavior pattern of compulsive drug use characterized by overwhelming involvement with the use of a drug and securing of the supply, as well as the tendency to relapse after completion of withdrawal.

Internet Addiction Disorder is the term first proposed by Dr. Ivan Goldberg for pathological, compulsive Internet usage. Internet Addiction Disorder is said that it is closest to pathological gambling. This is because some Internet users cannot control themselves when they should access or disconnect the internet. Many medical doctors and psychologists attempt to elucidate Internet Addiction Disorder. These explanations consist of psychodynamic and personality, sociocultural, behavioral and biomedical explanations. Notwithstanding, Ferris (2002) points out that during this time the term Internet Addiction Disorder is still difficult to define. Not all can perfectly elucidate any addiction and some are better than the others at explaining Internet Addiction Disorder. So far, researchers can only focus on defining the symptoms that lead into Internet addiction. 
Keith Beard Psy.D.The Gale Group Inc., Gale. "The Internet addiction disorder refers to the problematic use of the Internet, including the various aspects of its technology, such as electronic mail (e-mail) and the World Wide Web. Reader should note that Internet addiction disorder is not listed in the mental health professional's handbook, the Diagnostic and Statistical Manual of Mental Disorders, fourth edition, text revision (2000), which is also called the DSM.”

\section{OBJECTIVES}

The present research, the role of Mental Health among Internet addicts and non-addicts peoples.

- To identify the prevalence rate of mental health among internet addict and non-addict peoples.

- To study the role of mental health among male and female.

- To examine the interactional relationship between mental health among types of peoples and types of sex.

\section{METHODS AND MATIRIALS}

\section{Sample:}

For the purpose of the present (research) study, a sample consisting of 160,( In all) individual respondents were selected as a final sample from types of Peoples ( Internet addict and nonaddict) and types of sex (Male and female) were considered in the group of Male and female studying of Ahmadabad district of Gujarat state.

\section{Tools: following tools were used}

For the collection of the data, various research tools have, been used in the related studies. Researchers have collected the information regarding mental health.

\section{PERSONAL DATA SHEET:}

For information (Dependents variables and Independent variables) Mental health regarding types of internet addict and types of sex were collected data/samples by Personal data sheet.

\section{USED OF SCALE:}

The scales name to the Mental health Inventory (1992), The inventory is measuring 5 factors of mental health. The tool is measured by using the test and split-half method for 100 males \& females. The reliability is 0.94 \& by using the split-half method is 0.54 and validity is 0.63 at 0.01 level of significant.

Dr D. J. Bhatt (1992) it was Constructed, Standardize and administered to obtain data \& to check the effect question on mental health inventory 


\section{HYPOTHESES}

Following major hypothesis tested in present research.

HO1: There is no significant different between the mean score of Mental health of Internet Addict and non-Addict peoples.

HO2: There is no significant different between the mean score of male and female with regard to Mental health.

HO3: There is no significant interactive effect of Mental health among types of peoples and types of sexes .

\section{VARIABLES}

Dependent variables: Total Scores of respondents on Mental health inventory

Independent variables: Type of Peoples and Types of sexs as a Independent variables.

Research design: The 2 x 2 two-factor factorial research design adopted in the study

Table No.1: 2 X 2 research design as mental health as a related to different Type of People and Sex.

\begin{tabular}{|l|l|l|l|l|}
\hline \multicolumn{2}{|c|}{ Content } & \multicolumn{2}{c|}{ Classification of the Samples of types of sex } & Sc/St Class \\
\cline { 3 - 4 } & Male---B1 & Female---B2 & people \\
\hline \multirow{2}{*}{$\begin{array}{l}\text { Type of } \\
\text { peoples }\end{array}$} & Internet addict A1 & 40 & 40 & 80 \\
\cline { 2 - 5 } & Internet non- addict-A2 & 40 & 40 & 80 \\
\cline { 2 - 5 } & Total & 80 & 80 & 160 \\
\hline
\end{tabular}

\section{Major statistical techniques used:}

To analyze the data with related variables of $2 \times 2$, two-factor factorial research design and the 'ANOVA' applied in different variables.

\section{RESULTS AND DISCUSSION}

The scores on Mental health was analyzed as stated and basic satistics is as per below; Means and standard deviations for the different scores on Mental health, internet addict and non addicts and Sex variables of development are following shown in column diagram No.1-2, and tables No 1 to 4, discussion in the next page respectively. 
Column diagram No.1: The mean difference of types of peoples and Sex of Mental health among Ahmedabad district peoples.

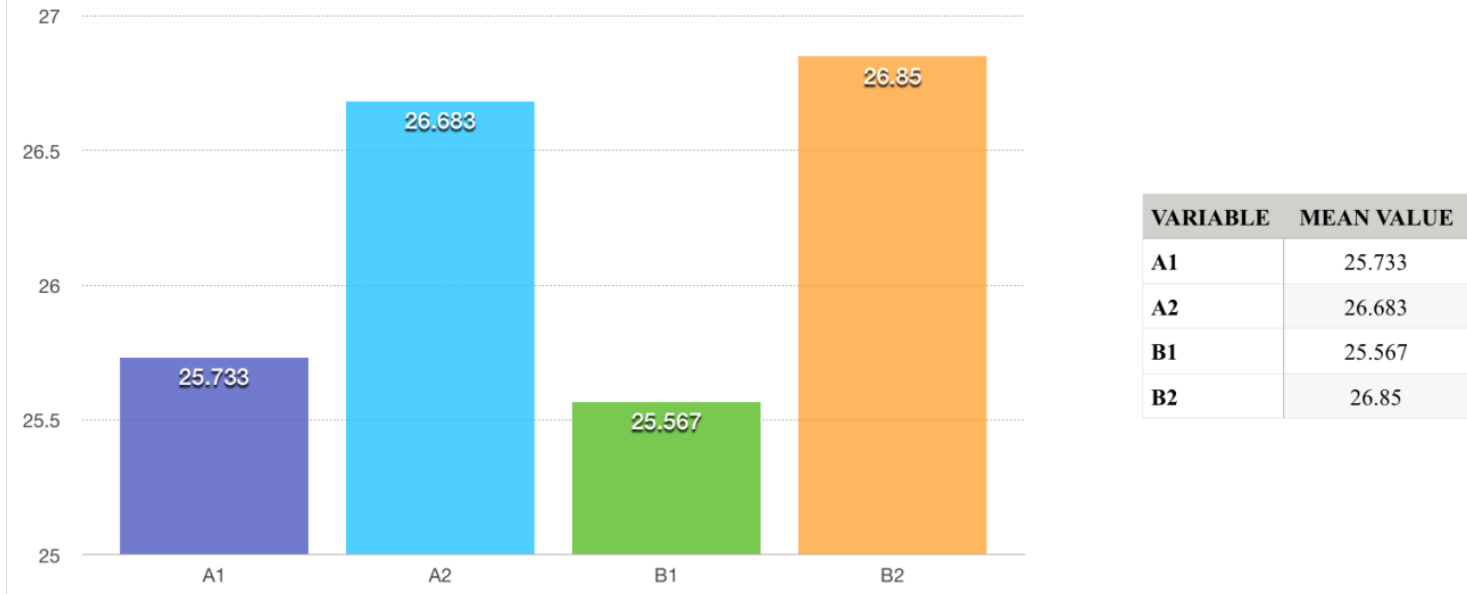

The above that is the column diagram no.1, shows that there were mean difference are A1 variables values of low of A2, it means the column A2 level is high is showed a significant improvement is their mean difference was 2.28, comparison to the internet addict peoples. B1 variables values of the low column of B2, as well as mean score comparison to the different was 1.27. There are four variables the highest mean score column of B2 and lowest score column of B1.

Column diagram No.2: Types of Peoples and Types of sex of mental health among Ahmedabad city

1000

100

\begin{tabular}{|l|c|}
\hline VARIABLE & MEAN VALUE \\
\hline A1B1 & 25.117 \\
A1B2 & 26.35 \\
A2B1 & 26.017 \\
A2B2 & 27.35 \\
\hline
\end{tabular}
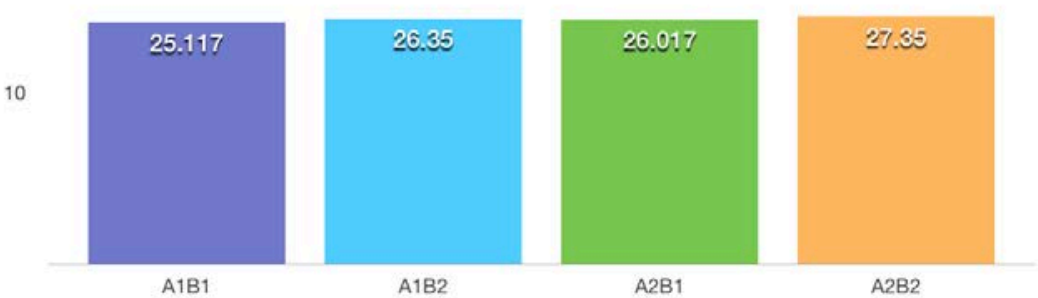

A2B2

27.35

The above that is the column diagram no.2, shows that there were mean difference are A1B1, internet addict male people variables and A1B2 internet addict female peoples values of high column diagram of A1B2, it means this A1B1 column diagram level is low, showed a significant improvement and their mean difference was 1.23. Comparison to the internet non-addict male peoples A2B1 variables values of the low level column of A2B2, as well as mean score comparison to the difference was 1.33 . There are four independent variables the highest mean score and highest column diagram level of A2B2 and lowest column diagram level of A1B1. 
Table No.2: Shows the analysis of variance (' $F$ ' test) of Mental health among internet addicts and non addict peoples.

\begin{tabular}{|l|l|l|l|l|l|}
\hline Source & $\begin{array}{l}\text { Type III Sum of } \\
\text { Squares }\end{array}$ & df & $\begin{array}{l}\text { Mean } \\
\text { Square }\end{array}$ & F & $\begin{array}{l}\text { Level of } \\
\text { Sig. }\end{array}$ \\
\hline $\begin{array}{l}\text { Addict and non-Addict } \\
\text { people }\end{array}$ & 108.3 & 1 & 108.3 & 3.45 & NS \\
\hline
\end{tabular}

df1 = $0.05-3.85,0.01-6.66 * * * * * * * * * * * * * * * * * * *$ df2 $=0.05-3.00,0.01-4.62$

Ho1: There is no significant different between the mean score of Mental health of Internet Addict and non-Addict peoples.

Table No.1, and 2, indicates that the mental health factors are the very important role in mentally effect of Internet Addict and non-Addict peoples. There are several types of peoples concept and conflict of different institution, organization, schools and family concerned over uses by the internet addict he has contact may be accessing, they time spend on maximum by the internet facility with mobile phones and Computers.

It can be seen from Table no. 2, indicates that the mean score of the internet addict peoples= 25.733 $(\mathrm{N}=40)$ and mean score of internet non-addict peoples was $=26.683(\mathrm{~N}=40)$, the difference between the 0.95 . The Ho1 tested this observation. it was found that the (mean ss 621.075) 'F'value was 3.45 for the type s of Peoples. which was not significant at any levels. Therefore the above, $\mathbf{H}_{\mathbf{0 1}}$ null-hypothesis was accepted and it was regard that the Internet Addict and non-Addict peoples have shown no difference in Mental health. And this difference is found no significant. It means in the present study it is seen that there is a no significant different in between Internet Addict and non-Addict peoples regard with mental health. The probable reason for this kind of results may be that in internet addict and non-addict people may be taking more care, may be more attentive to the his family and may be having more concerned compared to other general peoples. In internet addict peoples are very busy with internet facility or their job hence may not be able to pay more attention on their natural environment as results they may have developed more mental health compared to internet non-addict peoples. The result supported by the research of Goleman (1995), validated this further by stating that in developing emotional intelligence "we learn how to feel about ourselves and how others will react to our feelings; how to think about these feelings and what choices we have in reacting; how to read and express hopes and fears”. Along similar lines, another significant aspect that can explain this negative relationship is that of communication.

Table No3: Shows the analysis of variance (' $F$ ' test) of the Mental health among Gender.

\begin{tabular}{|l|l|l|l|l|l|}
\hline Source & Type III Sum of Squares & df & $\begin{array}{l}\text { Mean } \\
\text { Square }\end{array}$ & F & $\begin{array}{l}\text { Level of } \\
\text { Sig. }\end{array}$ \\
\hline Male and female & 197.633 & 1 & 197.633 & 6.295 & 0.05 \\
\hline
\end{tabular}

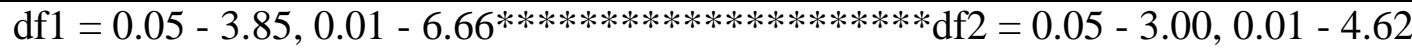


HO2: There is significant different between the mean score of male and female with regard to Mental health.

It can be seen from Table no. 4, indicates that the mean score of the male was $=25.567(\mathrm{~N}=40)$ and mean score of female was $=26.85(\mathrm{~N}=40)$, the difference between the 1.283. The $\mathbf{H}_{02}$ tested this observation. it was found that the 'F'value was 6.295 for the type s of sex. which was significant at 0.05 levels. Therefore the above, The probable reason for this kind of results may be that in sex of male and female may be taking more care, may be more attentive to his family and may be having more concerned compared to other. Table No.1, and 4, indicates that the Psychological problems such as mental health can reduce the quality of life. Therefore the technique which influence and decrease these emotional troubles can recover the our superiority of our existence effect of male and female as a types of sex. Check of the response above indicate with the intention of internet addict and non-addict inexperienced improved mental health about his environment of internet addict also questioner their performance in statistics and gene renal a more negative and unfavorable attitude towards male and female. Thus it is recommended that statistic instructors monitor the levels of mental health and apprehension experienced by their students and devise instructional strategies to deal with and reduce that mental health experienced in their statistics class (Gal and Ginsburge-1994-and Zhang et al.2012)

Table No.4: Shows the analysis of variance (' $F$ ' test) of the Mental health among types of people and Gender.

\begin{tabular}{|l|l|l|l|l|l|}
\hline Source & Type III Sum of Squares & df & $\begin{array}{l}\text { Mean } \\
\text { Square }\end{array}$ & F & $\begin{array}{l}\text { Level of } \\
\text { Sig. }\end{array}$ \\
\hline A X B & 0.3 & 1 & 0.3 & 0.01 & NS \\
\hline
\end{tabular}

df1 $=0.05-3.85,0.01-6.66 * * * * * * * * * * * * * * * * * * *$ df2 $=0.05-3.00,0.01-4.62$

HO3: There is no significant interactive effect of Mental Health among types of peoples and types of sex.

It can be seen from Table no. 4, indicates that the mean score of the types of people was $=27.31$ $(\mathrm{N}=80)$ and mean score of type of sex was $=27.31(\mathrm{~N}=80)$, the difference between the 0.00 . The HO3: tested this observation. it was found that the 'F'value was 0.401 for the type s of People and sex. which was not significant at any levels. Therefore the above, HO3: null-hypothesis was accepted and it was regard that the the types of People and sex shown no difference in Mental health effect of internet difference.

No differences were obtained in statistics Mental health between types of peoples and types of sex who had not taken a prior types of peoples and those who had not completed a prior nor types of sex. Zhang etal.-2012 found that medical students with higher levels of research 
experience and statistical education tended to have more positive attitudes. Thus it is recommended that internet facility will be provided for both levels there is no diseases of internet addict.

\section{CONCLUSION}

Following findings emerged after the interpretation of the data.

- The overall data calculate and analysis of types of people there is no significant effect on Mental health.

- There is a male and female as gender factors peoples there is significant results on Mental health.

- There is no significant role and relationships of types of people and types of sex on Mental health.

\section{LIMITATIONS}

The sample was drawn from different peoples like internet addict and internet non-addict, and male and female from Ahmadabad District of Gujarat State hence, it can be not applicable to whole India.

\section{SUGGESTION FOR FURTHER}

For comprehensive study of different types of internet addict and non addict and types of sex as a males and female may be included in the study so as to remove different internet addict and non addict biases.

\section{IMPLICATION OF THE STUDY:}

A profile of the different may be prepared to solve his problem of addicts and can predicted with the help of results, manipulated effectively to get better results with respect to different internet addict male and female and internet non addict male and female peoples.

\section{REFERENCES}

Keyes, Corey (2002). "The mental health continuum: from languishing to flourishing in life". Journal of Health and Social Behaviour 43 (2): 207-222.

Kitchener, BA \& Jorm, AF, 2002, Mental Health First Aid Manual. Centre for Mental Health Research, Canberra.. p 5

Matarazzo J.D., (1980). "Behavioural health and behavioural medicine frontiers for a new health psychology.” Journal of American Psychology US. 35, 807-817.

Mercado A.C., Carol L.J., Classidy J.D., Cote P. (2000). "Health Psychology" $5^{\text {th }}$ edition, Pearson Education, New Delhi, India, 333-338.

Richards, K.C.; Campania, C. Muse-Burke J.L (2010). "Self-care and Well-being in Mental Health Professionals: The Mediating Effects of Self-awareness and Mindfulness". Journal of Mental Health Counseling 32 (3): 247. 
Storrie, K; Ahern, K.; Tuckett, A. (2010). "A systematic review: Students with mental health problems-a growing problem". International Journal of Nursing Practice, 16(1), 16. 16 (1): 1-16.

\section{Webs}

- http://www.nimh.nih.gov/health/publications/mental-health-medications/completeindex.shtml

- http://tribune.com.pk/story/342616/mental-health-new-therapy-technique-teachesfamilies-how-to-cope/

- http://www.webmd.com/mental-health/mental-health-adjustment-disorder 